\title{
Anticonvulsant serum levels: relationship to impairments of cognitive functioning
}

\author{
PJ THOMPSON, MR TRIMBLE* \\ From the Department of Neuropsychiatry, The National Hospital for Nervous Diseases, Queen Square, \\ London UK
}

SUMMARY Twenty-eight patients with epilepsy were seen on two occasions at an interval of three months. On one session anticonvulsant serum levels were high and on the other session the serum levels were lower. On each of the two sessions patients performed a series of psychological tests and had a blood sample taken for the analysis of anticonvulsant serum concentrations. Seizure frequency in the previous three months was documented and several patients had an EEG recording made. Deficits in psychological test performance were found at high serum concentrations. Furthermore, lower serum level concentrations did not appear to be accompanied by worsened seizure control.

Anticonvulsant serum levels are thought to provide a better indicator of clinical response and the incidence of neurotoxic side effects in patients with epilepsy than doses of drugs. ${ }^{1}$ Therapeutic ranges have been established for several anticonvulsants within which maximum seizure control may be expected with minimum occurrence of side effects, such as nystagmus, ataxia, diplopia and mental confusion. ${ }^{2}$ However, it is unclear whether serum level monitoring may also prove useful for avoiding detrimental drug-induced changes in cognitive functioning which have been reported. ${ }^{3}$ In the assessment of the effects of these drugs on cognition only a few investigators have included measurements of anticonvulsant serum concentrations and several have reported impairments in association with high but not always toxic levels. ${ }^{4-9}$

The majority of studies have either compared the psychological test performance of two groups of patients, divided about some arbitrary cut-off value into high and low serum groups, ${ }^{56}$ or have correlated psychological test scores of a sample of patients with their individual serum concentrations. ${ }^{89}$ Interpretation of the findings from such studies unfortunately is complicated since many interrelated factors such as seizure severity and frequency, head traumas and psychosocial problems have been implicated as

Address for reprint requests: Dr MR Trimble, The National Hospital for Nervous Diseases, Queen Square, London, WC1 3BG, UK.

Received 15 July 1982 and in revised form 3 November 1982. Accepted 20 November 1982. influencing the cognitive state of patients with epilepsy. ${ }^{10}$ Patients with high anticonvulsant serum levels may well differ with respect to a number of such important parameters from patients with lower serum concentrations.

Investigations involving non-epileptic volunteers offers a partial solution to investigating drug effects as the contaminating influence of other epileptic variables is avoided. Authors have reported deficits in psychological test performance of normal volunteers at therapeutic and sub-therapeutic levels of phenobarbitone ${ }^{1112}$ and phenytoin. ${ }^{13}$ In our own research we have also found adverse effects of phenytoin at sub-therapeutic concentrations and for sodium valproate and carbamazepine less marked impairments at values within their respective therapeutic ranges. ${ }^{1415}$ Extrapolation from these acute drug studies involving non-epileptic individuals to patients with epilepsy, administered anticonvulsants chronically, must be made with caution. Detrimental effects recorded may reflect only transient impairments of functioning which may not be observed following more prolonged use.

To explore further the relationship between anticonvulsant serum levels and cognitive functioning, in particular whether adverse effects do occur at therapeutic concentrations, we have undertaken a study involving patients with epilepsy. To avoid the problems of interpretation of earlier investigations, a longitudinal design was adopted in which patients' performance on a series of specially designed psychological tests was measured at high and low 
anticonvulsant serum concentrations. The findings of this study are reported in this paper.

\section{Method}

\section{Patients}

Sixteen male and twelve female patients with a diagnosis of epilepsy participated in the study. No patient had undergone surgery in the past five years, had any signs of a progressive brain lesion or was prescribed any regular medication other than anticonvulsants. The mean age of the sample was 23.3 years (range 12-51) and their mean IQ was 99 (range 64-130). Three patients were still attending school or college and the remaining 27 had completed a mean of 11.4 years' education (range 9-16). The mean age of onset of epilepsy was 8.4 years (range 1-21) with a mean duration of 14.8 years (range $4-45$ ). Seizure type was primary generalised in six cases, secondary generalised in nineteen, partial in two and mixed in one. Sixteen patients were seen while attending a short-stay unit at a special centre for epilepsy and the remaining twelve were seen as outpatients at a neurological hospital. Patients were prescribed the same medication throughout the investigation; eight were taking phenytoin, five carbamazepine, five sodium volproate, three phenytoin and carbamazepine, two sodium valproate and carbamazepine, two primidone and carbamazepine, one primidone and phenytoin, one phenytoin and phenobarbitone and one primidone.

Design

All patients formed part of a larger investigation (Thompson-in preparation) and were seen on at least two occasions at three-monthly intervals. Following the first session patients had their $\operatorname{drug}(\mathrm{s})$ dosages raised or lowered for treatment reasons. The main investigator (PJT) was unaware of the direction of the change. On each session patients performed a series of psychological tests (see below) on completion of which a blood sample was taken for the analysis of anticonvulsant serum levels. In addition, their seizure frequency for the previous three months was documented and seventeen patients also had a twenty minute standard EEG recording made. The test performance of all patients was compared on a session in which the anticonvulsant serum concentrations of all the drugs they were receiving was high, to a session in which the serum level of the same drugs was lower. A second analysis was also undertaken excluding any patients with serum levels that exceeded the upper limit of the anticonvulsant therapeutic ranges.

\section{Psychological measures}

The psychological tests employed are outlined briefly having been described in detail elsewhere. ${ }^{14} 15$

1 Memory Twenty pictures and twenty words were displayed as slides at the beginning of each session. One minute and again one hour following the presentation of the last stimuli in each set, recall was tested. A yes/no recognition test was then administered in which the twenty original slides were presented in a random order with 20 new slides. A different set of stimulus items and recognition distractors was used on the two testing sessions.
2 Concentration (i) Stroop Test. The version used consisted of three cards. The task was to read the colour words (red, blue, green) on the first card (I) and to name the coloured rectangles (red, blue, green) on the second card (II) as quickly as possible. On the third card the colour words (red, blue, green) were printed in various colours (red, blue, green) never congruent with the word, and subjects were required to name the colour the words were written in as quickly as possible. The difference in the time taken to complete cards II and III and the number of errors made on card III were used as the measures of performance.

(ii) Visual scanning. The time taken to cancel a target digit from a page of random numbers was recorded in two conditions: (a) alone, and (b) in the presence of an auditory distracting task.

3 Mental speed (i) Perceptual speed. The minimum exposure duration at which subjects could recognise pictures of objects and words in a masking paradigm was used to assess the speed of perceptual registration.

(ii) Decision-making. Subjects' response latencies to simple questions either about the colour of an object (Is it red?) or more difficult ones about category membership (Is it a living thing?) were measured. The median reaction time for each question type was recorded.

(iii) A measure was also made of the visuo-motor component of the above task, that is the time taken to respond to light onset when no further decision was required.

4 Motor speed Tapping rate between two metal plates with a metal stylus was used to measure the speed of simple manual movements. Three conditions were investigated, tapping with the non-dominant hand, dominant hand and both hands simultaneously.

5 Subjective ratings On each session patients completed a Mood Adjective Check List which is a self-rating scale to assess their mood at the time of the psychological testing.

\section{Seizures}

Seizures were classified into three categories: first, tonicclonic attacks, both primary and secondary generalised; secondly, partial seizures, excluding any which were secondary generalised; and thirdly, other generalised attacks. For the patients at the Centre for Epilepsy, seizure frequencies were documented by trained personnel. The out-patient sample kept a record of their own seizures during the study and for the majority of these the completion of fit charts was already standard practice. No patient was seen within 48 hours of a tonic-clonic attack.

\section{EEG Recordings}

EEG recordings were performed on 17 patients and these were rated independently on a three-point scale as normal, moderately abnormal or severely abnormal.

Paired one-tailed $t$ tests were calculated for each of the measures of psychological test performance. Data from the MACL and seizure frequencies were analysed nonparametrically using Wilcoxon $t$ tests. Two sets of analysis were performed, the first involving the entire patient sample, and the second only involving non-intoxicated individuals. 


\section{Results}

\section{ANALYSIS 1}

Means and ranges of anticonvulsant serum levels of the 28 patients in the two sessions are given in table 1 . For 14 patients the high serum level session preceded the low level session by three months and for the remaining 14 the reverse was the case. With the exception of phenobarbitone in the high serum level session all mean serum levels were sub-toxic. The values for phenobarbitone also include values for patients receiving primidone.
Psychological Testing Means and standard deviations of the test scores in the two conditions and the results of statistical analysis are presented in table 2 .

Memory Immediate recall of pictures was significantly poorer at high serum levels $(t=-2 \cdot 18$; $p<0.05$ ) but no differences were observed on the delayed recall or recognition test. Immediate recall of words was also significantly worse at high serum levels $(t=02.20 ; \mathrm{p}<0.05)$ but again no effect was seen on the delayed recall or recognition test.

Table 1 Means and ranges of anticonvulsant serum levels ( $\mu$ molll) in the high and low level sessions $(N=28)$

\begin{tabular}{|c|c|c|c|c|c|}
\hline \multirow[t]{2}{*}{ Anticonvulsant } & \multirow[t]{2}{*}{$N^{*}$} & \multicolumn{2}{|c|}{ High level session } & \multicolumn{2}{|c|}{ Low level session } \\
\hline & & $\overline{\boldsymbol{x}}$ & Range & $\bar{x}$ & Range \\
\hline $\begin{array}{l}\text { Phenytoin } \\
\text { Phenobarbitone } \\
\text { Primidone } \\
\text { Carbamazepine } \\
\text { Sodium valproate }\end{array}$ & $\begin{array}{r}13 \\
1 \\
4 \\
12 \\
7\end{array}$ & $\begin{array}{r}65 \cdot 6 \\
177 \cdot 8 \\
56 \cdot 5 \\
38 \cdot 1 \\
487 \cdot 9\end{array}$ & $\begin{array}{c}28-129 \\
62-325 \\
44-69 \\
11-70 \\
161-1057\end{array}$ & $\begin{array}{r}42 \cdot 8 \\
107 \cdot 8 \\
24 \cdot 0 \\
24 \cdot 7 \\
296 \cdot 6\end{array}$ & $\begin{array}{c}15-69 \\
58-185 \\
18-31 \\
5-50 \\
70-634\end{array}$ \\
\hline
\end{tabular}

*Not addictive, several patients on more than one drug.

Table 2 Means $(S D)$ of the test scores in the high and low level sessions $(N=28)$

\begin{tabular}{|c|c|c|c|c|c|c|}
\hline \multirow[t]{2}{*}{ Psychological measures } & \multicolumn{2}{|c|}{ High level } & \multicolumn{2}{|c|}{ Low level } & \multirow{2}{*}{$\begin{array}{l}\text { Analysis } \\
t\end{array}$} & \\
\hline & $\bar{x}$ & $S D$ & $\bar{x}$ & $S D$ & & \\
\hline \multicolumn{7}{|l|}{ Attention } \\
\hline $\begin{array}{l}\text { Naming speed III-II } \\
\text { Errors }\end{array}$ & $\begin{array}{r}26 \cdot 2 \\
2 \cdot 9\end{array}$ & $\begin{array}{r}28 \cdot 8 \\
2 \cdot 2\end{array}$ & $\begin{array}{r}25 \cdot 3 \\
3 \cdot 0\end{array}$ & $\begin{array}{r}23.7 \\
2.4\end{array}$ & $\begin{array}{r}0 \cdot 25 \\
-0 \cdot 13\end{array}$ & $\begin{array}{l}\mathrm{L} \\
\mathbf{H}\end{array}$ \\
\hline \multicolumn{7}{|l|}{ Visual scanning } \\
\hline \multicolumn{6}{|l|}{ With auditory task } & $\mathbf{L}$ \\
\hline $\begin{array}{l}\text { Speed (secs) } \\
\text { Total no. scanned } \\
\text { Total no. errors }\end{array}$ & $\begin{array}{r}131 \cdot 6 \\
156 \cdot 6 \\
10 \cdot 0\end{array}$ & $\begin{array}{l}86 \cdot 9 \\
62 \cdot 3 \\
10 \cdot 8\end{array}$ & $\begin{array}{r}106 \cdot 3 \\
161 \cdot 9 \\
6 \cdot 8\end{array}$ & $\begin{array}{r}61 \cdot 5 \\
59 \cdot 3 \\
8.0\end{array}$ & $\begin{array}{c}2.59 \dagger \\
-0.97 \\
2.62 \dagger\end{array}$ & $\begin{array}{l}\mathbf{L} \\
\mathbf{L}\end{array}$ \\
\hline \multicolumn{7}{|l|}{ Mental speed (seconds) } \\
\hline $\begin{array}{l}\text { For words } \\
\text { For pictures }\end{array}$ & $\begin{array}{l}0.065 \\
0.069\end{array}$ & $\begin{array}{l}0.019 \\
0 \cdot 020\end{array}$ & $\begin{array}{l}0.064 \\
0.067\end{array}$ & $\begin{array}{l}0.017 \\
0.018\end{array}$ & $\begin{array}{l}0 \cdot 17 \\
0.91\end{array}$ & $\begin{array}{l}\mathbf{L} \\
\mathbf{L}\end{array}$ \\
\hline \multicolumn{7}{|l|}{ Decision-making } \\
\hline For colour & 0.960 & $0 \cdot 501$ & 0.809 & 0.335 & $2 \cdot 24^{*}$ & L \\
\hline For category & $1 \cdot 119$ & 0.606 & 0.876 & $0 \cdot 271$ & $2.82 \dagger$ & L \\
\hline $\begin{array}{l}\text { Visuo-motor response } \\
\text { Motor speed }\end{array}$ & 0.335 & 0.094 & $0 \cdot 292$ & 0.077 & $1 \cdot 84^{*}$ & $\mathbf{L}$ \\
\hline \multicolumn{7}{|l|}{ Tapping } \\
\hline $\begin{array}{l}\text { Dominant hand } \\
\text { Non-dominant hand } \\
\text { Both hands }\end{array}$ & $\begin{array}{l}67 \cdot 0 \\
60 \cdot 6 \\
53 \cdot 8\end{array}$ & $\begin{array}{l}12 \cdot 8 \\
12 \cdot 4 \\
11.9\end{array}$ & $\begin{array}{l}68 \cdot 6 \\
61 \cdot 8 \\
55 \cdot 2\end{array}$ & $\begin{array}{l}16 \cdot 1 \\
12 \cdot 8 \\
13 \cdot 1\end{array}$ & $\begin{array}{l}-0.89 \\
-0.70 \\
-0.66\end{array}$ & $\begin{array}{l}\text { L } \\
\text { L } \\
\text { L }\end{array}$ \\
\hline \multicolumn{7}{|l|}{$\begin{array}{l}\text { Memory } \\
\text { Pictures }\end{array}$} \\
\hline Immediate recall & $9 \cdot 2$ & 2.9 & $10 \cdot 2$ & 2.9 & $-2 \cdot 18^{*}$ & $\mathbf{L}$ \\
\hline Delayed recall & 7.8 & $3 \cdot 0$ & 8.7 & $3 \cdot 2$ & $-1 \cdot 55$ & $\bar{L}$ \\
\hline $\begin{array}{l}\text { Recognition }(\max =40) \\
\text { Words }\end{array}$ & $37 \cdot 4$ & $2 \cdot 9$ & $37 \cdot 0$ & $3 \cdot 5$ & 0.74 & $\mathbf{H}$ \\
\hline Immediate recall & $7 \cdot 5$ & 3.4 & 8.7 & $3 \cdot 3$ & $-2 \cdot 20^{*}$ & $\mathrm{~L}$ \\
\hline Delayed recall & $4 \cdot 7$ & $3 \cdot 1$ & 5.4 & 2.5 & -0.32 & $\mathbf{L}$ \\
\hline Recognition $(\max =40)$ & $31 \cdot 7$ & $4 \cdot 4$ & $31 \cdot 4$ & $4 \cdot 2$ & 0.32 & $\mathbf{H}$ \\
\hline
\end{tabular}

p $<<0.05 ;$ †p $<0.01$.

$\mathrm{L}=$ Impaired performance at high serum levels.

$\mathbf{H}=$ Better performance at high serum levels. 
Concentration Significant differences between high and low serum levels were observed on one measure of concentration. Patients took significantly longer to scan for visual targets when they were performing the auditory distracting task $(t=2.59 ; \mathrm{p}<0.01)$ in association with higher anticonvulsant serum concentrations.

Mental Speed (i) Perceptual Speed: No significant differences were observed between the high and low serum level sessions on the measures of perceptual speed.

(ii) Decision-making: On the decision-making test patients were significantly slower in making judgements about colour and category membership when their serum levels were high $(t=2.24 ; \mathrm{p}<0.05$; and $t=2.82 ; \mathrm{p}<0.01$ respectively).

(iii) Visuo-motor Response: There was also a significant increase in visuo-motor response latency at high levels $(t=1.84 ; \mathrm{p}<0.05)$.

Motor Speed There were no significant differences in tapping rate between the two sessions.

Subjective Ratings No significant differences in subjective ratings of mood were observed between the two sessions.

\section{Seizures}

Means and ranges of the number of seizures occurring in the three months before each session are given in table 3 . There were no statistically significant differences observed in seizure frequency before the high and low serum level sessions.

\section{EEG Recordings}

In the high serum level session, two patients' traces were rated normal, eleven moderately abnormal and four severely abnormal. In the low level session two patients' traces were rated normal, twelve moderately abnormal and three severely abnormal. There were therefore no major differences in the EEG traces taken on the two sessions.

\section{ANALYSIS 2}

Sixteen patients were not biochemically intoxicated from the sample of 28 and were included in the second analysis. The means and ranges of their anticonvulsant serum levels in the two sessions are presented in table 4. For seven patients the high serum level session preceded the low serum level session by three months and for the remaining nine the reverse was the case. Four patients were taking phenytoin, three carbamazepine, four sodium valproate, two phenytoin and carbamazepine, one sodium valproate and carbamazepine, one primidone and carbamazepine and one primidone.

\section{Psychological Testing}

Means and standard deviations on the psychological tests and the results of the statistical analysis are presented in table 5

1 Memory No measure of picture retention was influenced by the difference in serum levels. Patients, however, remembered significantly fewer words at high serum levels on the test of immediate recall $(t=-2.88 ; p<0.01)$ and delayed recall $(t=-2.69 ; \mathrm{p}<0.01)$. There was no significant difference between the two sessions on the word recognition test.

Table 3 Means and ranges of seizures occurring in the three months before the high and low level sessions $(N=28)$

\begin{tabular}{|c|c|c|c|c|c|c|}
\hline \multirow[t]{2}{*}{ Seizure type } & \multirow[t]{2}{*}{$N$} & \multicolumn{2}{|c|}{ High level session } & \multicolumn{2}{|c|}{ Low level session } & \multirow[t]{2}{*}{$P$} \\
\hline & & $\bar{x}$ & Range & $\bar{x}$ & Range & \\
\hline $\begin{array}{l}\text { Tonic-clonic } \\
\text { Other generalised } \\
\text { Partial }\end{array}$ & $\begin{array}{r}25 \\
4 \\
22\end{array}$ & $\begin{array}{l}3 \cdot 9 \\
179 \cdot 0 \\
28 \cdot 2\end{array}$ & $\begin{array}{l}0-16 \\
10-400 \\
0-150\end{array}$ & $\begin{array}{r}3.6 \\
153.0 \\
35.6\end{array}$ & $\begin{array}{l}0-18 \\
3-300 \\
0-300\end{array}$ & $\begin{array}{l}\text { ns } \\
\text { ns } \\
\text { ns }\end{array}$ \\
\hline
\end{tabular}

Table 4 Means and ranges of the anticonvulsant serum levels ( $\mu$ molll) of the non-intoxicated patients in the high and low level sessions $(N=16)$

\begin{tabular}{|c|c|c|c|c|c|}
\hline \multirow[t]{2}{*}{ Anticonvulsant } & \multirow[t]{2}{*}{$N^{*}$} & \multicolumn{2}{|c|}{ High level session } & \multicolumn{2}{|c|}{ Low level session } \\
\hline & & $\bar{x}$ & Range & $\bar{x}$ & Range \\
\hline $\begin{array}{l}\text { Phenytoin } \\
\text { Phenobarbitone } \\
\text { Primidone } \\
\text { Carbamazepine } \\
\text { Sodium valproate }\end{array}$ & $\begin{array}{l}6 \\
0 \\
2 \\
8 \\
4\end{array}$ & $\begin{array}{r}53 \cdot 2 \\
95 \cdot 0 \\
34 \cdot 0 \\
34 \cdot 3 \\
378 \cdot 8\end{array}$ & $\begin{array}{c}28-79 \\
65-128 \\
24-44 \\
18-47 \\
280-600\end{array}$ & $\begin{array}{r}32 \cdot 5 \\
61 \cdot 5 \\
27 \cdot 0 \\
20 \cdot 1 \\
175 \cdot 8\end{array}$ & $\begin{array}{l}15-60 \\
58-65 \\
23-31 \\
10-34 \\
70-343\end{array}$ \\
\hline
\end{tabular}

$* N=$ non-additive: several patients on more than one drug 
Table 5 Means $(S D)$ of the test scores in the high and low level sessions $(N=16)$

\begin{tabular}{|c|c|c|c|c|c|c|}
\hline \multirow[t]{2}{*}{ Psychological measures } & \multicolumn{2}{|c|}{ High level } & \multicolumn{2}{|c|}{ Low level } & \multirow{2}{*}{$\begin{array}{l}\text { Analysis } \\
t\end{array}$} & \\
\hline & $\bar{x}$ & $S D$ & $\bar{x}$ & $S D$ & & \\
\hline \multicolumn{7}{|l|}{ Attention } \\
\hline \multicolumn{7}{|l|}{ Stroop } \\
\hline Errors & $\begin{array}{r}21 \cdot 6 \\
2 \cdot 6\end{array}$ & $\begin{array}{r}15 \cdot 9 \\
2 \cdot 2\end{array}$ & $\begin{array}{r}24 \cdot 5 \\
2 \cdot 8\end{array}$ & $\begin{array}{r}15 \cdot 2 \\
2 \cdot 2\end{array}$ & $\begin{array}{l}-1.21 \\
-0.35\end{array}$ & $\begin{array}{l}\mathbf{H} \\
\mathbf{H}\end{array}$ \\
\hline \multicolumn{7}{|l|}{ Visual scanning } \\
\hline Speed (secs) & $113 \cdot 3$ & $84 \cdot 5$ & $100 \cdot 8$ & $56 \cdot 6$ & $1 \cdot 27$ & L \\
\hline \multicolumn{7}{|l|}{ With auditory task } \\
\hline Speed (secs) & $124 \cdot 1$ & $66 \cdot 1$ & $108 \cdot 2$ & $58 \cdot 6$ & $1 \cdot 86^{*}$ & L \\
\hline Total no. correct & 153.0 & $57 \cdot 3$ & 159.9 & $55 \cdot 5$ & -0.98 & $\vec{L}$ \\
\hline Total no. errors & 8.9 & 9.6 & 6.5 & $5 \cdot 5$ & 1.63 & $\vec{L}$ \\
\hline \multicolumn{7}{|l|}{ Mental speed (seconds) } \\
\hline \multicolumn{7}{|l|}{ Perceptual } \\
\hline For words & 0.064 & 0.019 & 0.067 & 0.019 & 0.97 & $\mathbf{H}$ \\
\hline $\begin{array}{l}\text { For pictures } \\
\text { Decision-making }\end{array}$ & 0.065 & 0.018 & 0.066 & 0.020 & $-0 \cdot 28$ & $\mathbf{H}$ \\
\hline \multicolumn{7}{|l|}{ Decision-making } \\
\hline $\begin{array}{l}\text { For colour } \\
\text { For category }\end{array}$ & 0.863 & $0 \cdot 223$ & $0 \cdot 789$ & 0.192 & $1 \cdot 35$ & $\mathbf{L}$ \\
\hline $\begin{array}{l}\text { For category } \\
\text { Visuo-motor response }\end{array}$ & $\begin{array}{l}1.053 \\
0.309\end{array}$ & $\begin{array}{l}0.351 \\
0.063\end{array}$ & $\begin{array}{l}0.901 \\
0.303\end{array}$ & $\begin{array}{l}0.213 \\
0.070\end{array}$ & $\begin{array}{l}2.31^{*} \\
0.34\end{array}$ & L \\
\hline Motor speed & & & & & & \\
\hline \multicolumn{7}{|l|}{ Tapping } \\
\hline Dominant hand & $67 \cdot 8$ & $13 \cdot 2$ & $68 \cdot 8$ & $17 \cdot 6$ & -0.46 & L \\
\hline Non-dominant hand & 59.8 & 12.4 & $61 \cdot 3$ & $14 \cdot 3$ & -0.66 & $\vec{L}$ \\
\hline Both hands & 58.4 & $10 \cdot 3$ & 57.7 & 13.8 & 0.33 & $\mathbf{H}$ \\
\hline \multirow{2}{*}{\multicolumn{7}{|c|}{$\begin{array}{l}\text { Memory } \\
\text { Pictures }\end{array}$}} \\
\hline & & & & & & \\
\hline Immediate recall & $8 \cdot 6$ & $2 \cdot 5$ & $9 \cdot 6$ & $2 \cdot 8$ & $-1 \cdot 19$ & L \\
\hline Delayed recall & 7.9 & $2 \cdot 6$ & $7 \cdot 8$ & $2 \cdot 9$ & 0.22 & $\overrightarrow{\mathbf{H}}$ \\
\hline Recognition (max $=40)$ & $37 \cdot 6$ & $2 \cdot 2$ & $37 \cdot 0$ & $3 \cdot 0$ & $0 \cdot 32$ & $\mathbf{H}$ \\
\hline \multicolumn{7}{|l|}{ Words } \\
\hline Immediate recall & $6 \cdot 3$ & $2 \cdot 8$ & $8 \cdot 3$ & $3 \cdot 0$ & $-2 \cdot 88 \dagger$ & $\mathbf{L}$ \\
\hline Delayed recall & 3.9 & $2 \cdot 6$ & $7 \cdot 8$ & $2 \cdot 9$ & $-2 \cdot 69 \dagger$ & L \\
\hline Recognition (max $=40)$ & $32 \cdot 1$ & $4 \cdot 2$ & 29.9 & $3 \cdot 8$ & 0.77 & $\mathbf{H}$ \\
\hline
\end{tabular}

${ }^{*} \mathrm{p}<0.05 ; \dagger p<0.01$.

$\mathrm{L}=$ Impaired performance at high serum levels.

$\mathbf{H}=$ Better performance at high serum levels.

Table 6 Means and ranges of seizures occurring in the three months before the high and low level sessions $(N=16)$

\begin{tabular}{|c|c|c|c|c|c|c|}
\hline \multirow[t]{2}{*}{ Seizure type } & \multirow[t]{2}{*}{$N$} & \multicolumn{2}{|c|}{ High level session } & \multicolumn{2}{|c|}{ Low level session } & \multirow[t]{2}{*}{$P$} \\
\hline & & $\bar{x}$ & Range & $\bar{x}$ & Range & \\
\hline $\begin{array}{l}\text { Tonic-clonic } \\
\text { Other generalised } \\
\text { Partial }\end{array}$ & $\begin{array}{r}13 \\
2 \\
13\end{array}$ & $\begin{array}{l}3 \cdot 2 \\
350 \cdot 0 \\
22 \cdot 2\end{array}$ & $\begin{array}{l}0-16 \\
300-400 \\
0-100\end{array}$ & $\begin{array}{r}2 \cdot 0 \\
325 \cdot 0 \\
20 \cdot 1\end{array}$ & $\begin{array}{l}0-10 \\
300-350 \\
0-180\end{array}$ & $\begin{array}{l}\text { ns } \\
\text { ns } \\
\text { ns }\end{array}$ \\
\hline
\end{tabular}

2 Concentration Patients took significantly longer to complete the visual scanning task when it was performed in conjunction with the auditory distracting task $(t=1.86 ; \mathrm{p}<0.05)$ in the high serum level session. No significant differences were observed on any other measures of concentration.

3 Mental Speed (i) Perceptual Speed: No effect of serum level was found on either measure of perceptual speed.

(ii) Decision-making: Slowing was observed on the decision-making task but the difference between the sessions was only significant for the more difficult decisions about category membership $(t=2 \cdot 31$; $<<$ 0.05).

(iii) Visuo-motor Response: No significant effect of the serum level change was recorded for the measurement of motor visuo-motor speed.

4 Motor Speed No significant differences between the sessions were observed on any of the three measures of tapping rate.

5 Subjective Ratings There were no significant differences in mood ratings between the high and low serum level sessions.

\section{Seizure Frequency}

Means and ranges of the number of seizures occurring in the three months before each session are presented in table 6 . No statistically significant dif- 
ferences in seizure frequency were observed in the three months prior to each session.

\section{EEG Recordings}

Only six of the sixteen patients had an EEG recording made on the two sessions. In the high level session one trace was rated as normal and five as moderately abnormal and in the low level session two were rated as normal and four as moderately abnormal.

\section{Discussion}

The results presented here suggest a relationship may exist between anticonvulsant serum levels and cognitive functioning. It is unlikely that these data reflect the influence of practice on the tests employed. First, almost equal numbers of patients were tested with a high or a low serum level first; secondly-and more importantly-the tests were designed to be as free as possible from practice effects (for further information on this see ref 14). In the first analysis, the mean scores of the 28 patients were lower on all but three measures in the high in comparison with the low serum level session, significant differences occurring on six. Impairment of performance seemed to be related to the demands of the task. Thus, on the visual scanning task a significant deficit at high serum levels was only recorded in the presence of the auditory distracting task and not when the scanning was undertaken on its own. Similarly, the degree of slowing on the decision-making test appeared related to the type of decision required with slowing being most marked for the more difficult category judgements.

These decrements of concentration and mental slowing seem likely to be related to the poorer immediate recall for pictures and words. The presentation of memory stimuli was experimenterpaced such that a reduction in attentional capacity or slowing would probably interfere with the adequate registration of stimulus items.

With the exception of phenobarbitone levels in the high serum level session the above impairments in test performance were observed at mean serum levels for the other anticonvulsants which were within their respective therapeutic ranges. Nevertheless several patients were biochemically intoxicated in the high serum level session and accordingly the results obtained may merely reflect the value of keeping within these ranges to avoid adverse effects on cognitive functioning. The findings of the second analysis indicated that this was not entirely the case and that decrements in test performance also occurred at sub-toxic serum concentrations. However, impairments were less marked, with poorer scores associated with high serum levels on only 12 measures, and of these four were significant. As in the previous analysis deficits were observed on the more demanding tasks; visual scanning in the presence of the auditory distracting task and category decision-making.

In contrast a different pattern of results occurred on the memory recall tests, which seemed related to the type of material rather than the time of testing. Thus, impairments were observed on both the immediate and delayed recall test for words and not, as before, on the immediate recall tests for pictures and words.

There was little evidence to suggest the pattern of results obtained was related to seizure frequency since there was no significant difference in the number of seizures occurring in the three months prior to the high and low serum level sessions in either analysis. Nor was there any suggestion that the impairments observed at high serum levels were associated with a deterioration in EEG traces although available information was limited.

The findings discussed here are consistent with those of other investigators referred to earlier who reported deficits of cognitive functioning with high serum levels of anticonvulsants. The lesser, but nevertheless significant, changes in the second analysis need a more cautious interpretation, since the sample size was reduced. However, the suggestion that serum anticonvulsant levels within the so-called therapeutic range may lead to subtle impairments of cognitive function has been suggested by several authors, ${ }^{49}$ and we suggest that further exploration of the effects of these drugs on cognitive function and behaviour at such levels seems warranted. In particular, our study does not enable any conclusions to be drawn about individual anticonvulsants since only a few patients were treated with single drugs, but comparisons between drugs in patients is clearly desirable in future research. In addition these data do not allow us to comment on the influence of polytherapy itself on cognitive function, although data at present in preparation does suggest that, when compared with monotherapy, combinations of anticonvulsant drugs may contribute to cognitive problems in epilepsy. ${ }^{16}$

It is important to note from our investigations that deficits in performance in association with high serum levels were generally not noted until the psychological test became more exacting, and it seems likely that such impairments would be overlooked in a standard out-patient interview, even using ordinary clinical assessments of the mental state. In order to adequately assess the influence of anticonvulsants on cognitive functioning in patients with epilepsy, future research should be carried out 
using drug sensitive measures. This approach would also enable more information to be gathered about possible differences between individual drugs in their effects on cognition, and also enable adverse effects to be balanced against the beneficial effects of the drugs on seizure frequency.

The authors acknowledge support from a locally organised research grant (National Hospitals) and the Thorn Epilepsy Fund. We also greatly thank Dr J Oxley, of the Chalfont Centre for Epilepsy, for his cooperation and help throughout the study.

\section{References}

${ }^{1}$ Reynolds EH. Serum levels of anticonvulsant drugs: interpretation and clinical value. Pharmacol Ther 1980;8:217-36.

${ }^{2}$ Eadie MJ, Tyrer JH. Anticonvulsant therapy: pharmacological basis and practice. London, Churchill Livingstone, 1980.

3 Trimble MR, Reynolds, EH. Anticonvulsant drugs and mental symptoms: a review. Psychol Med 1976;6:169-78.

${ }^{4}$ Reynolds, EH, Travers RD. Serum anticonvulsant concentrations in epileptic patients with mental symptoms. Br J Psychiatry 1974;124:440-5.

5 Matthews CG, Harley JP. Cognitive and motor sensory performances in toxic and non-toxic epileptic subjects. Neurology (Minneap) 1975;25:184-8.

${ }^{6}$ Dodrill CB. Diphenylhydantoin serum levels, toxicity and neuropsychological performance in patients with epilepsy. Epilepsia 1975;16:393-600.

' Macleod, CM, Dekaban AS, Hunt E. Memory impairment in epileptic patients: selective effects of phenobarbitone concentration. Science 1978;202:1102-4.

${ }^{8}$ Diehl LW. Treatment of complicated epilepsies in adults. A clinical statistical study. Basel, Karger, 1979.

9 Trimble MR, Corbett JA. Behavioural and cognitive disturbances in epileptic children. Ir Med J 1978,Suppl 1,73:21-8.

${ }^{10}$ Dikmen S. Neuropsychological aspects of epilepsy. In: Herman, BP (ed). A Multidisciplinary Handbook of Epilepsy. Springfield, Charles C Thomas, 1980;3673.

${ }^{1}$ Hutt SJ, Jackson PM, Belsham AB, Higgins G. Perceptual-motor behaviour in relation to blood phenobarbitone level. Dev Med Child Neurol 1968;10:626-632.

12 Houghton GW, Latham AN, Richens A. Differences in the central actions of phenytoin and phenobarbitone in man, measured by CSF thresholds. Eur J Clin Pharmacol 1973;6:57-60.

${ }^{13}$ Ideström CM, Schalling D, Carlquist V, Sjöquist F. Behavioural and psychophysiological studies: Acute effects of diphenylhydantoin in relation to plasma levels. Psychol Med 1972;2:111-20.

14 Thompson PJ, Huppert FA, Trimble MR. Phenytoin and cognitive function: effects on normal volunteers and implications for epilepsy. Br J Soc Clin Psychol 1981;20:155-62.

15 Thompson PJ, Trimble MR. Sodium valproate and cognitive functioning in normal volunteers. $\mathrm{Br} J$ Clin Pharm 1982;12:819-24.

${ }^{16}$ Thompson PJ, Trimble MR. Anticonvulsant drugs and cognitive functions. Epilepsia 1982;23:531-44. 